\title{
'Living with' air pollution in Abidjan (Cote d'Ivoire): a study of risk culture and silent suffering in three occupational areas
}

\author{
Sylvia Becerra $^{\mathrm{a} *}$, Marie Belland ${ }^{\mathrm{b}}$, Alain Bonnassieux ${ }^{\mathrm{c}}$ and Catherine Liousse ${ }^{\mathrm{d}}$ \\ ${ }^{a}$ Géoscience Environnement Toulouse, Université de Toulouse, CNRS, IRD, UPS, Toulouse, \\ France; ${ }^{b}$ Université de Strasbourg, Dynamiques Européennes, Strasbourg, France; ${ }^{c}$ Dynamiques \\ Rurales, Université Jean Jaurès, Toulouse, France; ${ }^{d}$ Laboratoire d'Aérologie, Université de \\ Toulouse, CNRS, UPS, France
}

\begin{abstract}
Ambient air pollution is currently a major environmental health hazard in many urban areas across the African continent. Driven by the increased concentration of human activities in cities, occupational exposure represents one of the main risk factors to disease burden. Consequently, 'living with' air pollution is a significant daily life public health issue. In this study, we focus on three specific occupational sites in Abidjan, Côte d'Ivoire, representing different major pollution sources - road traffic, wood fires and waste-burning fires. We explore in particular the social experiences of people exposed to chronic air pollution as well as the distribution of health risks across different occupational sources. We assessed the characterization of the 'risk culture' of workers, studying if it varies according to participants' occupations and how it influenced their exposure. Our analysis combines a qualitative assessment of the 'risk culture' of air pollution with the development of a Risk Culture Indicator (RCI). We show firstly that the working conditions and occupational practices in each group shape specific representations of air pollution, varying levels and emphasis within understandings of risk as represented within the RCI scores. We also demonstrate that occupational status in each group plays a role in reducing exposure to air pollution, with those most vulnerable socio-economically remaining the most exposed. Finally, the findings suggest that risk culture is the combination of a tangible experience of air pollution and other risks encountered in daily life, technical mediations shaping that experience (objects and equipment), as well as existing power relationships. These considerations of risk culture should be considered as an integral part in assessment of health risks.
\end{abstract}

Keywords: risk culture; air pollution; occupational health; Africa; urban environment

\section{Introduction}

Ambient air pollution is currently a modern environmental health hazard in urban Africa and beyond (Nweke \& Sanders, 2009). Such pollution is estimated to cause more than 3 million premature deaths worldwide each year through cardiovascular diseases, respiratory illnesses and cancers, according to the World Health Organisation [WHO] (2016).

The primary objective of the work presented here, was to understand the ordinary social experience of air pollution in Abidjan city, particularly in three occupational groups exposed to air pollution in the areas studied in the DACCIWA programme (https://www.dacciwa.eu/). Another longer-term objective was to develop a tool to assess

*Corresponding author. Email: sylvia.becerra@get.omp.eu 
the 'risk culture' of pollution to integrate sociological and environmental data with a view to modelling environmental and social interactions.

Our findings are based on a qualitative assessment of the 'risk culture' of air pollution (interviews in three occupational groups) with the development of a Risk Culture Indicator (RCI). We show firstly that the working conditions and occupational practices in each group shape specific practices and representations of air pollution. The RCI scores underline the social and occupational inequalities with regard to air pollution. Indeed the data suggest that occupational status in each group plays a role in reducing exposure to air pollution, with those most vulnerable socio-economically remaining the most exposed. Our findings emphasise a more holistic approach to the operational assessment of environmental health risks.

\section{Rethinking risk at the interface of daily life and work}

In recent literature, 'living with' risk is presented as the major challenge facing contemporary societies (Boudia \& Jas, 2013; 2015), which have to find their own resilience pathways in an environment 'polluted forever' (Torny, 2013). These approaches examine the transformation in governance arrangements of sanitary and environmental risks caused by the development of new technologies over the twentieth century. 'Government through adaptation' is described by Boudia and Jas $(2013,2019)$ as the mode of regulation, which, given the irreversibility of contaminations and the omnipresence of dangers, equips urban dwellers with the tools and devices to face, or in this case attempt to 'live with' the risks. In other words, it is not so much about mastering pollution than organising ways of living on permanently polluted territories coupled with a discourse on individual responsibility in risk management: because it is not possible to avoid contaminants, each person is urged to reduce his or her own exposure (Boudia \& Jas, 2013). Risk culture is one of the recommended tools: it is a set of cognitions of risks (including perception, awareness, understanding and memory), behaviours and practices for preventing risks or avoiding dangers (Blesius, 2013; Durand, 2014). Risk culture was in that sense defined by Giddens as 'a fundamental cultural aspect of modernity, in which awareness of risk forms a medium of colonizing the future.' (Giddens, 1990, p. 244).

However, living with risks does not presuppose that exposed individuals have a perception or awareness of the environmental risks nor does it assume the individuals' development of effective precautionary measures. In line with the Tulloch and Lupton's analysis (2003, p. 1), we argue that the understanding of risks, and therefore the ways in which risk is dealt with and experienced in everyday life, should be considered from a sociocultural perspective, through both culture and personal experience.

Considering that Giddens defined the concept of 'risk culture' within the western context, we question the empirical foundations and expectation of risk culture in a nonwestern context. If responses to environmental threats involve coping or adaption strategies to better manage the future, it is important to recognise that not all societies and individuals have the same coping capacities. Difficulties in coping and surviving in the present may limit possibilities for avoiding risk for future planning as other studies have noted (Becerra, Saqalli, Gangneron \& Dia, 2016; Tulloch \& Lupton, 2003).

We defined 'living with the contamination risk' in the oil rich Amazon basin of Ecuador as the social capacity to cope with the difficulties of daily life related to oil industry activities such as oil spills and chronic contamination of soil, air and water - which sometimes includes using the environmental contamination to obtain financial or in kind compensation. We 
argued that within this context, risk culture is 'a cognitive and behavioural resource, which can be regarded as practical "capital" that can be mobilised to address risks' (Becerra, Juteau-Martineau, Maestripieri, \& Maurice, 2016, p. 203). While the lack of behaviour change responses to environmental risk is often considered 'irrational' by outsiders, in this case, it reflects a holistic approach to handling risks, since environmental risks are embedded in other daily and visible risks (Desmond, Prost, \& Wight, 2012; Van Voorst, 2015). We considered that people face a variety of hazards and risks, not only from their natural environment, but also related to their daily activities such as education, employment and the like, as suggested in other research (Lin \& Chang, 2013; Tulloch \& Lupton, 2002; Wisner, Blaikie, Cannon, \& Davis, 1994/2004). Thus, risk culture consists of the knowledge and experiences required to identify and prioritise what is risky, the assessment skills needed to measure threats in real time (how risky something is) and the ability to act (how to act on something happening now) in order to make plans for the future while feeling relatively safe. The influence of culture, political engagement, employment and personal experiences with dangers are parameters taken into account in the development of a 'culture of contamination risk' (Becerra, Saqalli, Gangneron, \& Dia, 2016).

The exposure to air pollution and associated risks, which are a significant feature of African cities, are not only directly linked to social and working conditions but also to an ambiguous relationship with employment. Although it is a means of economic sustenance and social resilience, work also poses health risks. As Hecht noted (2019, p. 2), 'under conditions of scarcity, the need for employment trumps the need for clean air'. Yet, assessing these risks requires moving beyond the idea of a 'faulty perception of risk' (Revet \& Langumier, 2015), to understand what constitutes 'ordinary coping'. We chose to characterise risk culture for the people in various occupations who are daily exposed to urban pollution, given the lack of a truly effective collective response to the problem (Belland, 2017). 'Ordinary coping' herein means the usual strategies or efforts employed in chronic exposure contexts in which people are confronted with air pollution associated risks and nuisances as well as with the many forms of threats and challenges posed by their daily activities.

Adopting this theoretical framework in the global South, one could intuitively be inclined to analyse the situation in terms of poverty and social hierarchy. In this work, however, such an approach has not been chosen. Following the precepts of pragmatist sociologists (Barthe et al., 2013; Lemieux, 2018), we did not presume the effects of social inequalities in handling risks. Pragmatist sociologists underline that 'to be described properly, asymmetries cannot be prejudged' (Barthe et al., 2013, p. 194). We aimed to understand what actors do concretely when they encounter practical situations in which they are exposed to pollution and the sanitary risks arising from risks.

\section{Understanding Abidjan and its development}

Abidjan, the economic capital of Côte d'Ivoire, has a population of approximately $4,288,000)$. The city was originally limited to a few Ébrié villages. The rapid growth of the Ivorian economy until the end of the 1970s triggered an influx of Ivorians from all ethnic groups and regions of the country, as well as foreign workers, mainly from Burkina Faso and Mali. This very diverse population has established itself in highly varied housing areas ranging from residential areas occupied by the Ivorian and expatriate elites, to medium-standard and affordable housing districts mainly intended for Ivorian employees from the upper- and lower-middle classes, to old working-class 
neighbourhoods and informal, poorer settlements housing a high proportion of the immigrant population.

During the economic crisis and due to the political and military conflicts (from 1999 to 2010) poverty levels increased, the sanitary conditions worsened, and the tensions between Ivorians and immigrants grew. Many migrants were prevented from taking some jobs in the informal sector. Housing and roads deteriorated, especially in the affordable working-class districts and in informal settlements. At the same time, the city area expanded from $580 \mathrm{~km}^{2}$ in 1990 to 2,199 $\mathrm{km}^{2}$ in 2010 (Yao-Kouassi, 2010), which has resulted in a greater disconnection between housing and employment areas. A dramatic reduction in employment opportunities in the modern sector and impoverishment in the population have led to the expansion of northern neighbourhoods (Abobo-Gare, Anyama) and the areas west of the Banco Forest (Yopougon, Adjamé, Attecoubé), where land and house prices are lower (almost two-thirds of the Abidjanese population). Despite the stabilisation of state institutions and the economic recovery since Alassane Ouattara's election in 2010 (and re-election), the informal sector continues to account for 75 percent of jobs according to a study conducted by the Observatoire de l'Emploi in 2008. Amongst these, the fish smoking (home fires) and waste recovery activities studied here, belong largely to the domain of subsistence micro-activities.

In this context, urban transport has evolved to become much more informal (KassiDjodjo, 2010) and pollutant (Liousse, Assamoi, Criqui, Granier, \& Rosset, 2014). Home and dump fires are further quickly increasing air pollution sources (Keita et al., 2018; Xu et al., 2019) (Figure 1), which the Ivorian State fails to address. We found national public policies unable to regulate polluting activities or assist exposed citizens effectively due to excessive fragmentation, lack of funding and the long-lasting prioritisation of cleanliness at the expanses of health within environmental governance.

As data on air pollution in major African cities remain very limited, an environmental and epidemiological study was launched in 2014 in Abidjan through the DACCIWA

\section{Black Carbon emissions (TgC/yr)}

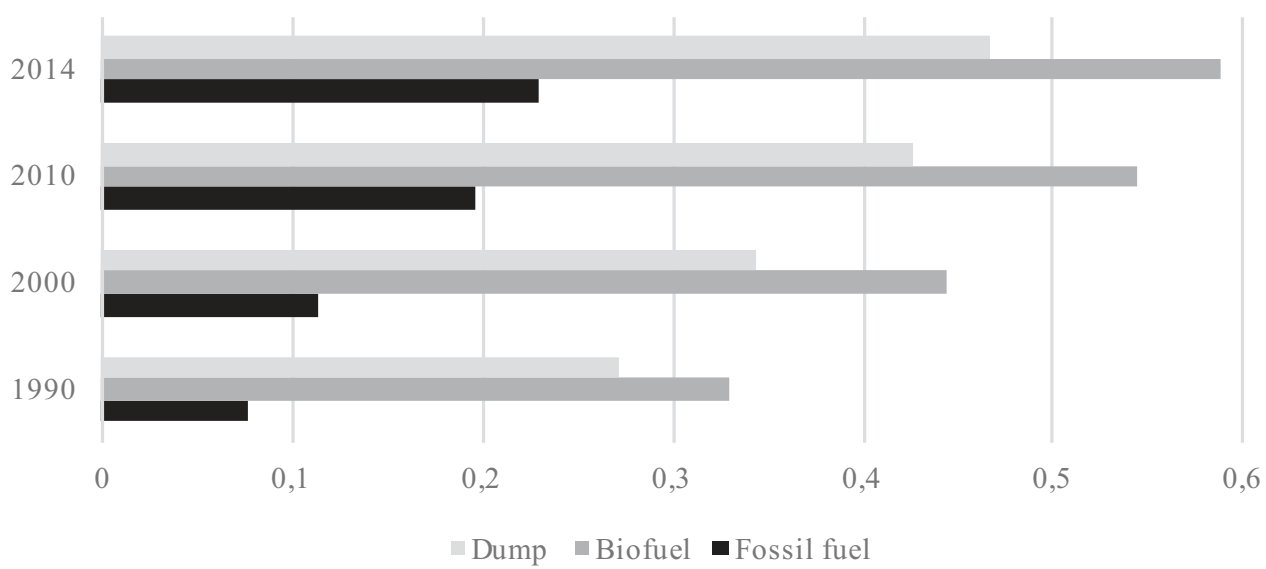

Figure 1. Emissions of black carbon between 1990 and 2014 Changes in emissions of black carbon, a particulate pollutant, from three sources (fossil fuel, dump and biofuel emissions) between 1990 and 2014 (data from [author(s)]. Dump emissions include all African waste burning sources as for Akouedo site and fossil fuel sources include traffic emissions. 
research programme. High gaseous and particulate air pollution levels produced by a growing concentration of human activities such as home fires and traffic were exposed in the research programme. Unless actions are taken to regulate emission sources, those emissions and their associated mortality and morbidity will likely increase over the next decade (Liousse et al., 2014).

Unfortunately, the study does not currently include the social dimensions of these environmental risks, limiting the study's scope for an integrated assessment and management of health risks. How do representations and social practices contribute to air pollution? How do exposed persons face this risk and protect themselves against it?

\section{Methods}

The underlying consideration upon which our study was based was that risk culture regarding air pollution is linked to daily life and working conditions and serves less to 'colonise the future' as expressed by Giddens (1990), than to negotiate the various ordinary sources of risk in the everyday present. Another assumption states that combining an understanding of the effects of living conditions with those of environmental contamination would help us to assess how health risks were approached from a more holistic perspective (Barraza et al., 2017).

In this study we focused on three occupational groups exposed to different major pollution sources in Abidjan (Figure 2): namely women fish and meat smokers in Yopougon (exposed to biofuels), taxi drivers in Adjamé (exposed to fossil fuels from road traffic), and dump site workers in Akouédo (exposed to sources of waste-burning). We based our analysis on the following forms of primary data:

\section{Semi-structured interviews}

In these interviews we focused on the social representations of risk against the background of personal and occupational contexts; behaviours, practices and actions associated with living with pollution (individual or collective action); and the participants' capacity for self-projection into the future.

We relied on key informants who facilitated access on the ground. Primary data was collected during two field surveys (exploratory field survey in July 2016; long-term survey from February to May 2017). Around sixty original interviews were conducted with workers with different characteristics regarding age, gender, nationality, years on the job at the study site, and social status in the job. Individual interviews, rich in socio-biographical information were supplemented through focus groups to assist us in characterising power relationships, competition, mutual aid and other social relationships in each occupational area. 'Contextual' interviews were also carried out with key informants in the occupational areas under study (members of trade unions and trade associations; representatives of public institutions) to understand the relationship between the occupational groups and the local area and the socio-political context in which these occupations are carried out. The field observations and interviews were transcribed and their content was analysed using grounded theory based on a qualitative thematic analysis (Bardin, 1977).

A Risk Culture Indicator (RCI) was also implemented. It was inspired by the original methodology and findings of previous and exploratory works based on Giddens's definition of risk culture (Calès, 2016; Racinés, 2017) that led us to identify the following four main components (see details in Supplementary Material): 

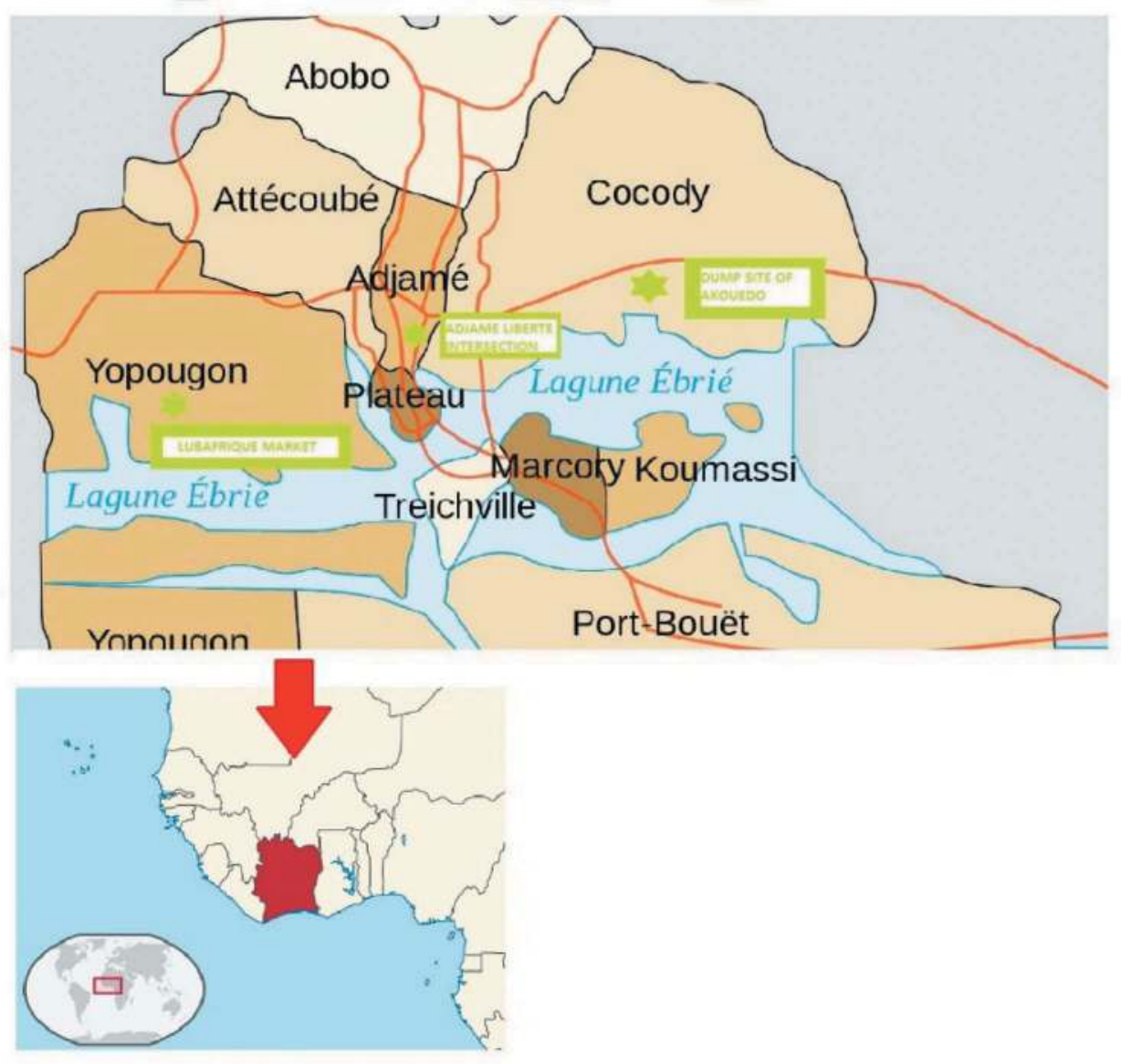

Figure 2. Study sites localisation.

(1) context and conditions strengthening or weakening the perception of risk in accordance with the idea of a social amplification of risk (Renn, Burns, Kasperson, Kasperson, \& Slovic, 1992)

(2) understanding and representations of risk;

(3) the "living with" pollution (individual practices);

(4) strategies and self-projection into the future.

On this basis, the initial RCI was redesigned to consider the specific aspects of the living with air pollution issue: each of the four components was subdivided into various items (see SM).

\section{Applying an RCI to each individual and occupational group of our study}

Each of the items for the RCI was given a value according to the adequacy between the RCI criteria and the interviewee's situation using the transcription of the interviews and field observations. We gave the value 0 when the person did not meet the criteria; the value 1 when the person met the criteria; and the in-between value of 0,5 for a nuanced 
answer. Each individual's final indicator was the sum of all the values, that is a score between 0 and 16. If any items could not be given a value based on the interviews, a weighting coefficient was applied to the final score. We assume that a higher RCI (16: the highest) would mean a greater ability to evaluate one's risk of exposure to air pollution and to embrace the future. On the other hand, a person with a low RCI score ( 0 : the lowest) is to be considered 'vulnerable' to air pollution. The formal representation of individual or group RCIs as radar diagrams, beyond their scores, was expected to reveal the internal structure of their risk understandings - in terms of each component's contribution to the RCI values - and was used to draw comparisons across individuals and occupational groups.

\section{Findings}

\section{Socio-economic characteristics of study sites}

(1) Women fish and meat smokers in Lubafrique market. Lubafrique, located in the working-class commune of Yopougon, served as an example of a market run by and for women. Approximately thirty women fish and meat smokers worked on a smoking site on the edge of the market. The space was structured according to an age-related hierarchy, which determined social status: older smokers who owned their businesses (called 'mums'), their paid employees and younger home helps, often teenagers who were dependent on and learned from their elders.

(2) Taxi drivers in Adjamé-Liberté, one of the largest intersections in the city of Abidjan. A hierarchy existed between owners, incumbent, assistant and casual drivers. These categories differed in their social recognition, with the owner, when not driving his taxi, employing a so-called incumbent driver (titulaire) who drove the vehicle and had to pay the owner a fee of CFAF 17,500 (approx. €27) out of his daily takings, making his living from what he earns beyond that lump sum after paying for fuel. The incumbent driver in turn chose an assistant driver (second), who was attached to the same owner and with whom he took turns driving the vehicle. Finally, the incumbent and assistant drivers hired out their taxi to casual drivers (occasionnels).

(3) Dump workers in Akouédo. Previously located outside the city of Abidjan, the dump (in operation since 1965) has become a part of the city and a complex economic system developed around it. The dump site was a dangerous place: waste was deposited without being sorted first and recovery activities were frequently carried out without protection. Workers were exposed to pulmonary and infectious diseases and subjected to a significant and permanent risk of accidents and immediate physical harms. Waste was regularly burned, which resulted in the release of considerable amounts of pollutants into the atmosphere. In addition, the ground has been contaminated since 2006 by the dumping of toxic waste from the Probo Koala tanker: 528 cubic metres of liquid waste offloaded in the port of Abidjan were transferred onto tanker trucks and dumped in 18 different locations around Abidjan.

Four subgroups were surveyed in this research site: waste pickers; multiple-job workers, combining in particular waste picking with market gardening or waste processing; service workers involved in waste transport or catering; and waste buyers who were active in the wholesale of recovered materials to factories in the Yopougon industrial zone. 


\section{The Lubafrique smokers: vulnerability was deliberately transferred to lower social status home helps}

The mean RCI attributed to the smokers was 9.42/16, with a standard deviation (SD) of 1.75 . The mean RCI for the mums receiving help $(10.83 / 16)$ was higher than for the mums without assistance (9.07/16); the average score for employees was $10.13 / 16$; while home helps had the lowest results (8.39/16; home helps accounted for five out of the six RCIs below 8/16).

The analysis of smokers' interview data and RCIs (Figure 3) showed a high awareness and understanding of the risk posed by air pollution, which was linked to the strong sensory experience of inhaling smoke when working close to smoking kilns in a confined space. They described the multitude of effects on the body in detail:

[The smoke] heats the body and smokes the eyes. So when you're there [at the smoking site], you feel the heat in your body because you're in contact with fire and you can feel burning. And it affects the eyes, you can't see properly anymore. (Ivorian owner of a smoking business, March 2017)

\section{RCI composition for Lubafrique smokers according to occupational status}

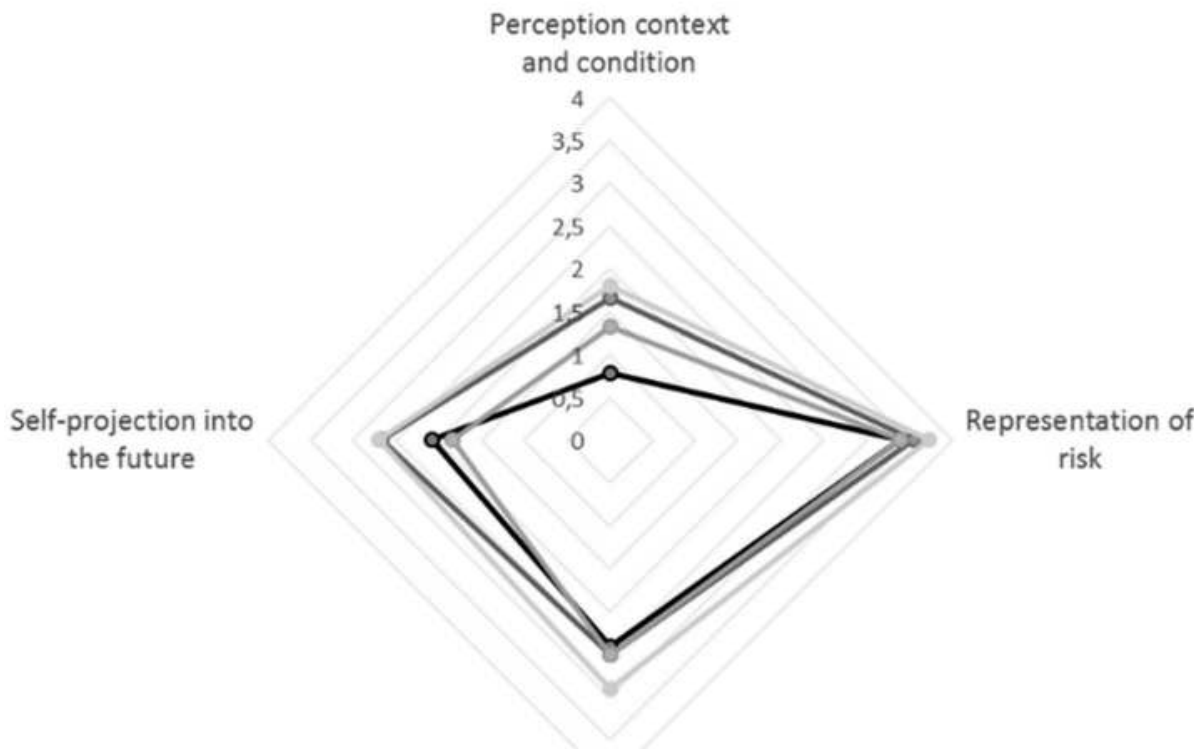

Living with pollution

$\multimap$ Home helper $\multimap$ Employed helper $\multimap$ Smokers without help $\longrightarrow$ Smokers with help

Figure 3. RCI composition for Lubafrique smokers according to occupational status (source: the authors). 
Perceptions of smoke were rather homogenous among smokers: 'smoke is dirty' and 'smoke is hot'. The smokers also suspected that smoke had an impact on their eyes, bodies, skin texture and colour, but also for some, on their menstrual cycle. These social representations of the impacts of air pollution were embedded in the uniform work gestures performed for smoking the fish and the identical equipment (recycled metal drums for ovens). The smoking site was also essentially a female space where the older mums passed on these representations to the younger women (employees and home helps) who conformed to the views and smoking practices conveyed by their elders (according to the primogeniture principle). The collective and shared knowledge produced by the mums also focused on the steps to mitigate the effects of pollution, in terms of which remedies would alleviate the effects of smoke on the body. Mums promoted self-medication with a combination of medicines, tonics, specific ailments and beverages to the younger workers.

We understand these strategies, which mums put in place to reduce exposure, as strengthening pre-existing dominance relationships and creating socio-environmental inequalities. This interpretation is informed by the composition of the smokers' RCIs. There was a distinction between the smokers receiving help and employed helpers, on the one hand, who had higher RCIs (mean RCIs above 10/16), and on the other hand, the smokers with the lower social status of home helps (whose scores were significantly below 10) and those without helps, with lower RCIs. Interestingly, field observations showed that the number of hours spent daily on the smoking site was higher on average for home helps (6 hours) than for the other categories. In the sample of respondents, the average time spent on site per working day was 3.5 hours for mums and 4.5 hours for employed helpers, which we assumed translates into higher exposure levels.

From an empirical perspective, protection against smoke was not compatible with a smoking job, since the smokers considered it inconvenient to wear protective equipment when doing the smoking; for instance, a mask was too hot, it restricted vision and made it hard to breathe; wearing equipment was also perceived as being inefficient: 'Protect me against smoke? With fish, I don't see how you could do it. To protect yourself, you can't stay by the fire, you'd have to keep away.' (Ivorian home help, February 2017). Furthermore, there were no plans to change work practices by using alternative fuels or improved smoking kilns as these were thought to alter the taste of the produce or to reduce income.

Moving away from the smoking site was the only option that was considered feasible to reduce their health vulnerability, either by seeking work elsewhere, by setting up their own trading business (employed helpers and home helps), or by employing someone else to do the smoking job in front of the oven while they sold the smoked produce in a more sheltered position away from the smoking area (mums). These strategies were reflected in the RCIs in terms of differing abilities to self-project into the future between mums with helpers (mean 'self-projection into the future' RCI component of 2.67/4), who were able to meet the self-projection objective, and mums without helps $(1.83 / 4)$ and between employees (2.67/4) and home helps (2.08/4).

We interpreted our data as showing that women who were initially the most vulnerable socially are also those who were the most exposed to pollution, as they were the least able to retreat from it. This social vulnerability appeared to be due to internal power relationships within the group. The home helps were often very young, without a salary and were not included in mutual support structures outside the family, since they were dependent on other 
family members. In short, we considered occupational autonomy as an important factor in reducing vulnerability to pollution, since it translates into a greater or lesser ability to exert control over working conditions and to carry out other tasks (instead of staying on the smoking site). Within a group that seemed at first evenly exposed to the health effects of air pollution, aged-related hierarchies of status shaped different levels of exposure, creating inequality with regard to environmental health hazards.

\section{The Abidjanese taxi drivers: a 'mechanistic' approach to pollution forged by individual practices}

Our calculated RCIs for taxi drivers (Figure 4) were higher than for the other sites: there were no RCIs below 7/16 and the group mean was 9.74/16. Medium and high results were moderately dispersed ( $\mathrm{SD}=1.85$ ). Comparing RCIs by status, there was an increase from assistant drivers and casual drivers with the lowest mean RCIs (respectively 8.95/16 and 9.1/16), to incumbent drivers (mean RCI of 10.38/16) and then to owners, with a very high mean RCI (13.18). Standard deviations within the subgroups ranged between 0.96 and 1.27 .

When carrying out their job, the Abidjanese taxi drivers in our study faced multiple economic, physical, social and operational risks, the impacts of which were exacerbated by the lack of a social security system and non-existent employment contracts. Faced with risks perceived as major, such as accidents or assaults, air pollution was seen as a secondary problem or even simply as an 'ordinary inconvenience' to be tolerated or resisted rather than prevented.

The RCIs of taxi drivers appeared to be strongly influenced by 'living with' and 'understanding and representations of pollution' components across all driver subgroups. Such uniform results could be attributed to the occupation itself: the vehicles were similar, as were journey fares and the regulations governing the sector. In addition, drivers who did not own their vehicles were under pressure from their 'bosses' to pay a daily fee. They were forced to drive from 6 a.m. until after 8 p.m., which partly explains polluting practices - that is practices which increased fuel consumption and particulate emissions (De Vlieger, De Keukeleere, \& Kretzschmar, 2000): erratic driving, longer hours driving, reducing the engine rest periods or use of adulterated fuel. On the issue of pollution representations in the industry, taxi drivers possessed detailed knowledge of the consequences for air quality of vehicle defects and maintenance, such as air filter cleaning, engine type and fuel quality. Their representations of protective measures against pollution effects were thus seen through this mechanical lens: the only approach that they considered feasible to protect themselves against air pollution was to have an air-conditioned vehicle so that they could shut themselves inside the car to avoid direct exposure to exhaust fumes.

When thinking about the future, exposure to air pollution was also a minor variable. In most cases, drivers referred to their desires to move up the industry hierarchy and become owners, while continuing to drive - and to be exposed to pollution - to maximise revenue. The variety of hazards faced led to their necessary prioritisation; for some drivers, this even reduced their time horizon since the priority was the day's income (short-term economic risk). We found this to be particularly evident among assistant drivers who were sometimes faced with sudden job changes.

Finally, occupational status, which we defined by ownership of the work tool, was seen as a determining factor for understandings of risk. The RCI levels we attributed to 


\section{$\mathrm{RCl}$ composition for taxi drivers according to occupational status}

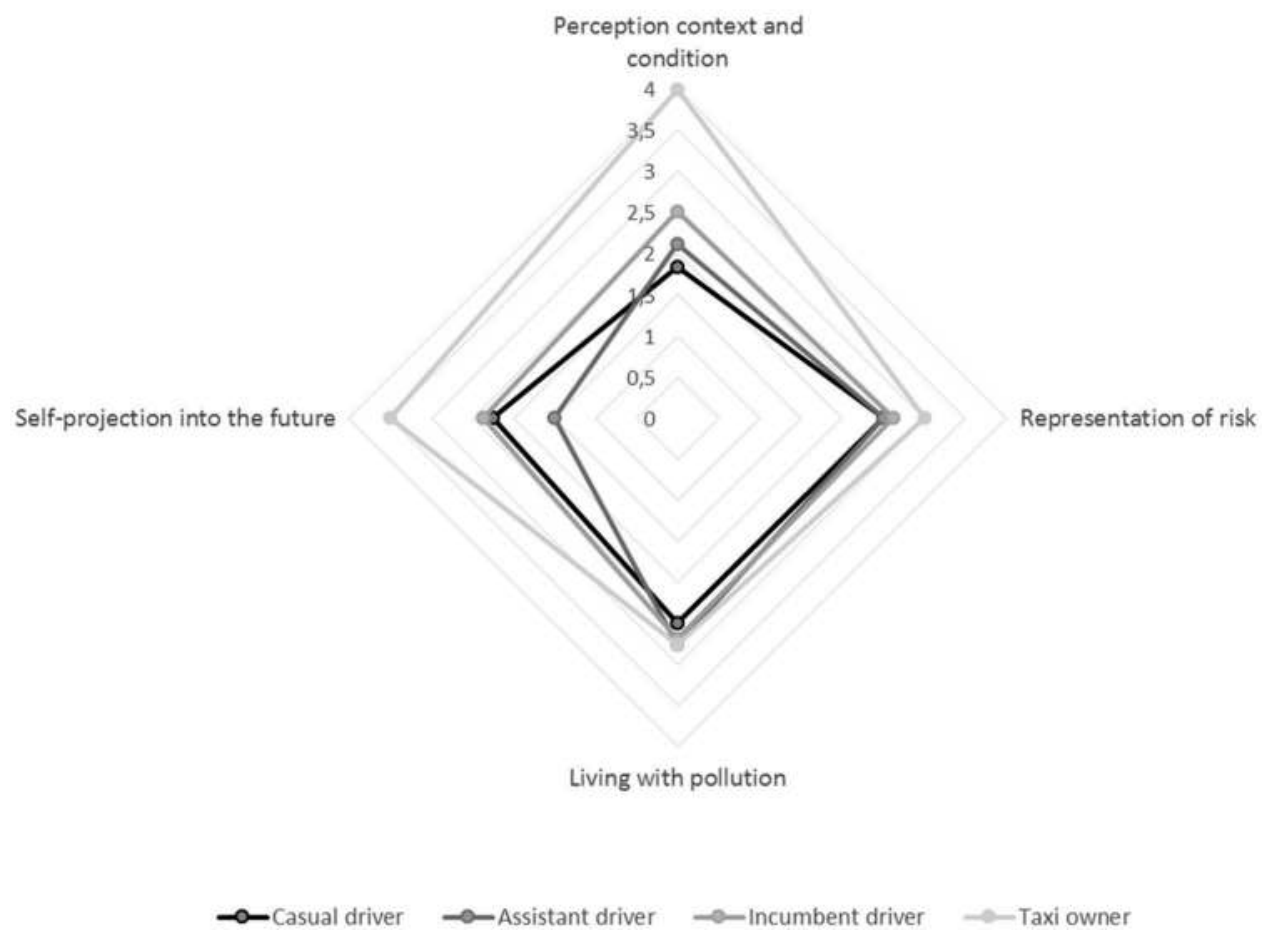

Figure 4. RCI composition for taxi drivers according to occupational status (source: the authors).

the owners were much higher than those of other status categories (Figure 4). We explain this 'higher' risk culture in terms of possibilities to participate in collective organisations, extensive experience in the job and a higher income - meaning for this group that they were not restricted by their financial means in the present, and they could provide for their family in the future. Their 'self-projection into the future' component also set them apart as they had the financial, cognitive, social network, and other resources needed to plan and carry out personal projects and could think about the future of the industry as a whole. Conversely, most other drivers resorted to individual strategies to improve their living conditions and reduce their level of exposure. Those were favoured over collective strategies because of the highly fragmentation of the industry. Taxi-drivers stressed that economic-oriented associations (tontines) or organisations assembling a minority of privileged drivers were the only link between them.

\section{The Akouédo dump site workers: air pollution was hidden by economic issues}

Comparing RCIs between jobs at the dump revealed high inequalities (Figure 5). Waste pickers with only one activity stood out strongly against other workers as having extremely low RCIs (6.49/16 on average). The average RCI we recorded for buyers 


\section{RCI composition for dump site workers according to occupational status}

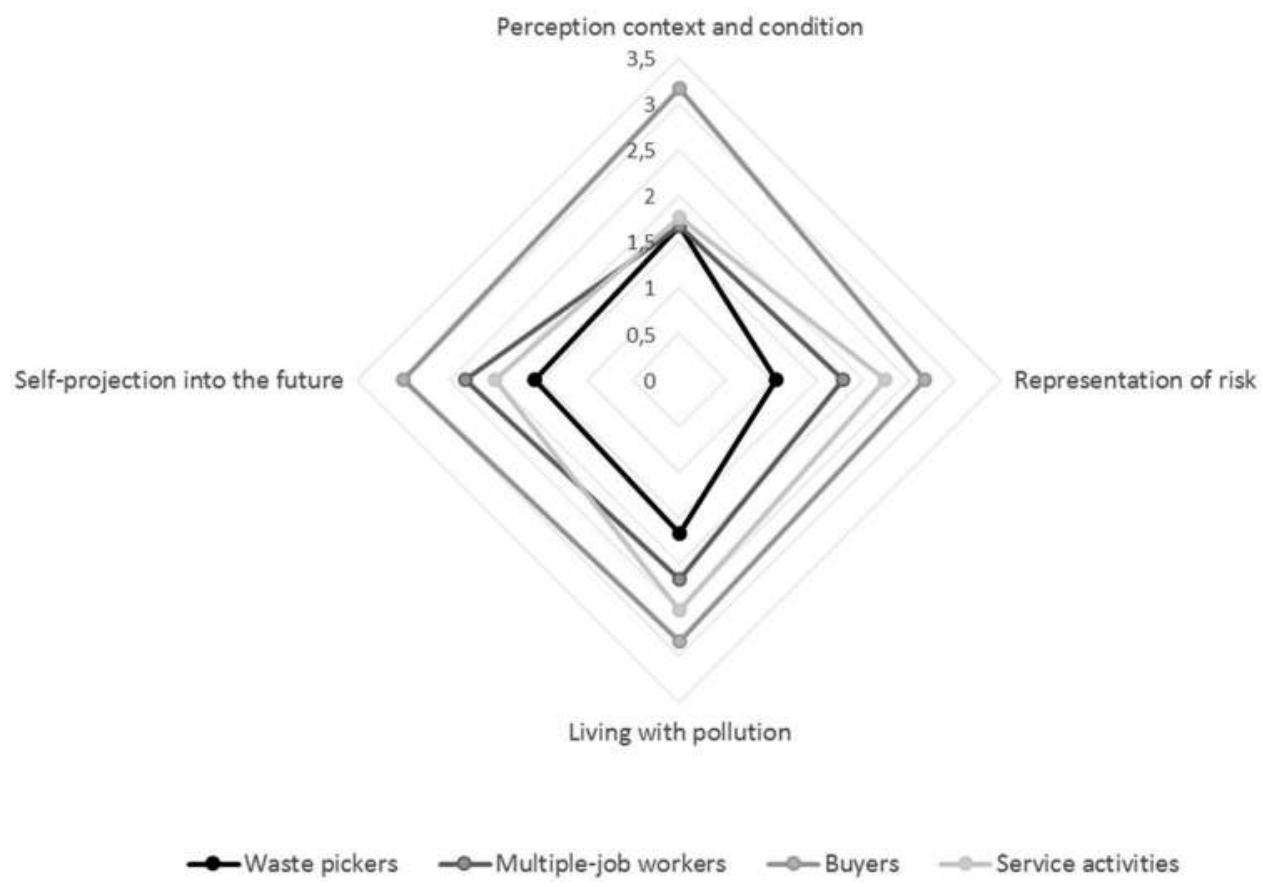

Figure 5. RCI composition for dump site workers according to occupational status (source: the authors).

was very high, at $11.89 / 16$, that is, two points more than workers offering catering and waste processing services $(8.89 / 16)$ and workers carrying out multiple activities in addition to waste picking and recovery $(8.27 / 16)$. The dump was the site with the lowest mean RCI (8.81/16) and the highest standard deviation (2.59).

Buyers achieved the highest results across all RCI components. We interpreted this as illustrating the case described by Giddens (1990) of a group experiencing danger, but which has managed to control its exposure both by understanding its surrounding environment and reducing its overall vulnerability.

We argue that a 'culture of danger' (Turner, 1981), rather than a culture of risk, had evolved among the dump workers: in practice, the occupational groups distinguished between different types of danger, giving priority to the most immediate hazards and considering the most extraordinary ones with a degree of fatalism. We observed the deprioritisation of the air pollution risk as reflected in waste pickers' RCIs in terms of very low scores for the 'awareness and understanding of pollution risk and its impacts' component (1.05/4 on average while scores below 2 were rare for other study sites), with waste pickers being the most directly exposed group.

Our data collected among waste pickers and multiple-job workers indicated that they considered their main challenge as reversing their unfortunate social and economic 
insecurity by changing the risks they were experiencing into opportunities. The interview data lead us to argue that the environmental health risks were recast as opportunities, as other work on environments associated with a pollution risk has shown (Becerra et al., 2016). An important finding in this sense was that references to the dump as being dangerous were displaced in workers' accounts by references to the dump as a 'lifesaving', a place of opportunities, and as providing work, income and even luck: 'We can't say it's not risky, but if you're earning a living there, you can't say it makes you ill. This work saves me' (Burkinabe woman with multiple jobs: waste picker and vegetable grower, April 2017).

An attentiveness to power relationships within the context of the dump helped us to explain this situation. The dump waste pickers with a single job, often immigrants from the sub-region, were in a situation of emergency and insecurity; for them, the dump is the only place where they could get a job and earn a living. Turning daily challenges and risks into opportunities was a form of resilience in the dump's highly risky environment, from which they could not escape.

Differences in RCI scores between the three groups (waste pickers, multiple-job workers and buyers) for the 'awareness and understanding of risk', 'practices for living with pollution' and 'self-projection into the future' components showed an association between the waste workers' social status and their RCI levels. There was a gradual increase in results for these components (higher RCIs) as social status rises. For instance, for the 'self-projection into the future' component, waste pickers were noted to have a reduced time horizon (their indicator for 'self-projection into the future' was 1.57/4), while workers who did not depend only on waste picking and recovery for a living were observed to have a slightly higher result ( $2 / 4$ for service activities and 2.33/4 for waste pickers with several jobs). Buyers with employees, who could choose not to be physically present at the dump, had an average result of 3/4. RCI scores for the 'perception context and condition' component were low and uniform for the three worker categories present at the dump site every day; such scores reflect the weakness of factors likely to increase their knowledge of pollution risks. These categories included a large proportion of older people, women and children. Some of these children belonged to the second and even the third generation of work pickers on the dump. Working on the dump for several decades appeared to foster minimal mobility. We consider this inability to extricate themselves economically from the dump environment as confining individuals and families to a situation of 'captive awareness' in their relationship with their contaminated environment (Becerra 2016).

\section{RCIs differ according to occupation and occupational status}

Comparing data (Figure 6) across the different occupational groups and sub-groups shows firstly that occupation is a critical factor for risk culture. Mean RCI values differed between the three occupations studied. The RCI values were 8.73/16 for dump site workers, 9.42/16 for smokers and 10.21/16 for taxi drivers with a substantial standard deviation for dump site workers $(\mathrm{SD}=2.59)$ signifying a large range of RCI levels, while the taxi drivers $(\mathrm{SD}=1.86)$ and smokers $(\mathrm{SD}=1.75)$ exhibited a narrower spread of $\mathrm{RCI}$ levels.

In addition, we observed a specific RCI structure for each occupation. The Figure 7 is a reminder of the jobs carried out by occupation and occupational status, with corresponding RCI values. The fish and meat smokers' example were the most illustrative in this respect, the cognitive component of their RCIs being much higher than their other 


\section{Comparison of RCI composition between the three occupations studied}

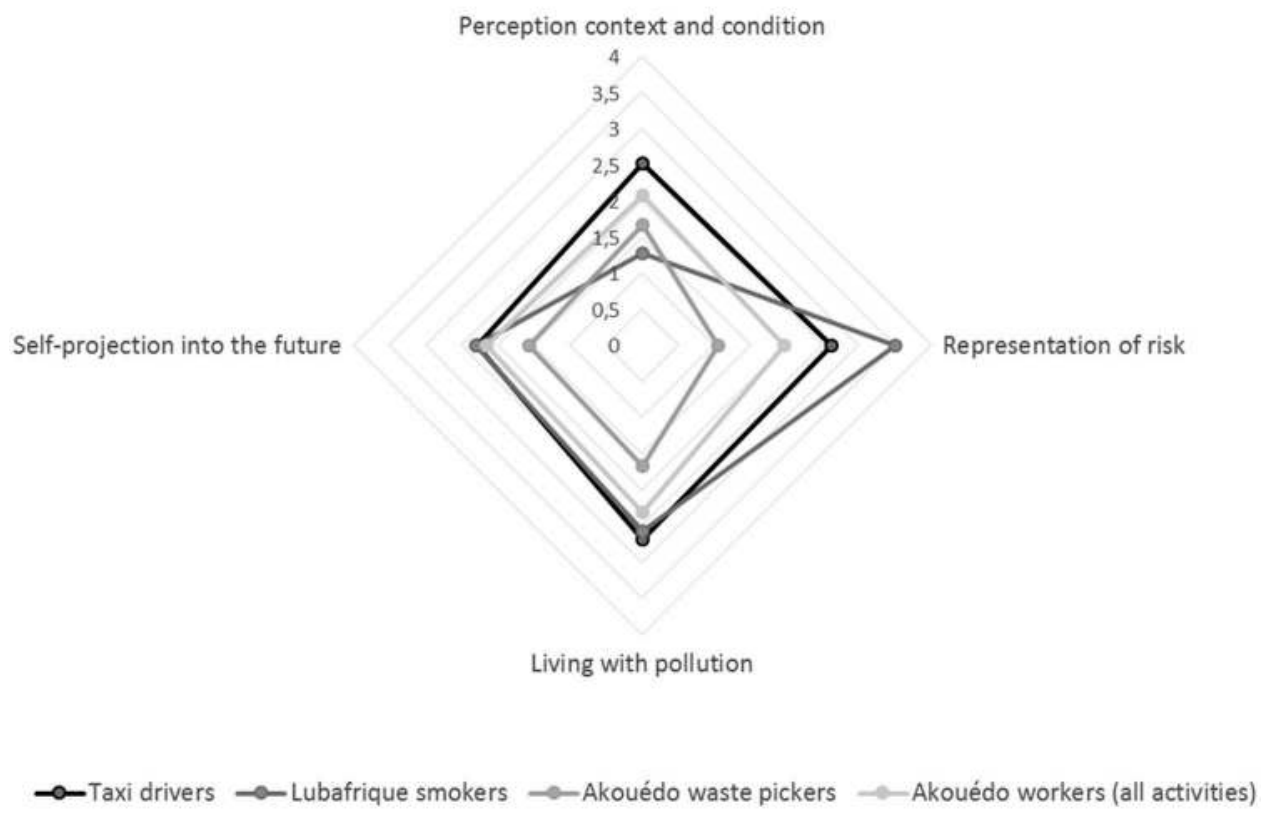

Figure 6. Comparison of RCI composition between the three occupations studied (source: the authors).

components. Although their RCI levels were lower than those of the taxi drivers, their awareness and understanding of risk was much greater than other groups. We considered the characteristics of their job, involving direct and continuous exposure to combustion sources and thus higher exposure to organic carbon and black carbon emissions, as pertinent to explaining why these participants had better 'incorporated' (as developed by Bourdieu, 1979; 1980) the health effects of air pollution but also its social effects.

\section{Coupling occupational and environmental exposure: do RCIs vary depending on emissions?}

In order to characterise emissions to which the various populations under study were exposed, we selected emission factor values for particulates of all sizes (TPM for 'total particulate matter'). Emission factors represent the amounts of particulates released into the atmosphere for each source under study, per $\mathrm{kg}$ of burned product: timber for the women smokers, waste for the dump site workers or fuel consumption for taxi drivers. Interestingly, the first study by $\mathrm{Xu}$ et al. (2019) evaluating particulate exposures of women smokers, children living on the dump and taxi drivers, all equipped with portable instruments, showed a consistent relationship between the emission factors used here and the exposure levels of the various populations. 


\begin{tabular}{|c|c|c|c|c|}
\hline Study site & Occupation & Job description & \begin{tabular}{|c|} 
Mean RCI \\
per \\
occupational \\
status
\end{tabular} & $\begin{array}{l}\text { Mean RCI } \\
\text { per } \\
\text { occupational } \\
\text { sector }\end{array}$ \\
\hline $\begin{array}{l}\text { Lubafrique smoking } \\
\text { site }\end{array}$ & \multirow[t]{2}{*}{$\begin{array}{l}\text { Smoker } \\
\text { receiving help }\end{array}$} & \multirow{2}{*}{$\begin{array}{l}\text { Owner of drums to smoke meat and fish, } \\
\text { employing helpers (employees or home } \\
\text { helps). Deals mostly with selling the } \\
\text { produce. }\end{array}$} & \multirow[t]{2}{*}{11.5} & \multirow[t]{5}{*}{9.42} \\
\hline \multirow{4}{*}{$\begin{array}{l}\text { Confined space } \\
\text { organised around fish } \\
\text { and meat smoking } \\
\text { kilns; smokers are } \\
\text { directly exposed. } \\
\text { Market run by and for } \\
\text { women }\end{array}$} & & & & \\
\hline & $\begin{array}{l}\text { Smoker } \\
\text { without help. }\end{array}$ & $\begin{array}{l}\text { Smoking drum owner working alone. } \\
\text { Carries out smoking and selling tasks. }\end{array}$ & 8.53 & \\
\hline & $\begin{array}{l}\text { Employed } \\
\text { helper }\end{array}$ & $\begin{array}{l}\text { Young woman employed on a daily basis by } \\
\text { a mum to smoke a given quantity of } \\
\text { produce. }\end{array}$ & 9.6 & \\
\hline & Home help & $\begin{array}{l}\text { Young woman working for her mother, aunt } \\
\text { or sister. She is unpaid, but provided with } \\
\text { food and accommodation. }\end{array}$ & 8 & \\
\hline $\begin{array}{l}\text { Adjamé-Liberté } \\
\text { Intersection }\end{array}$ & Owner & $\begin{array}{l}\text { Owner of one or more vehicles. Few drive } \\
\text { their vehicle. }\end{array}$ & 13.18 & \multirow[t]{4}{*}{10.21} \\
\hline \multirow{3}{*}{ 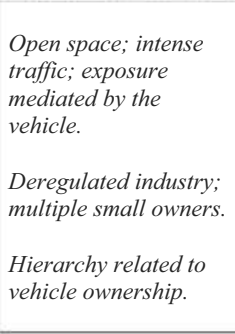 } & $\begin{array}{l}\text { Incumbent } \\
\text { driver }\end{array}$ & $\begin{array}{l}\text { Taxi driver chosen by the owner. Borrows } \\
\text { the latter's vehicle in exchange for a daily } \\
\text { fee. }\end{array}$ & 10.38 & \\
\hline & $\begin{array}{l}\text { Assistant } \\
\text { driver }\end{array}$ & $\begin{array}{l}\text { Taxi driver chosen by the incumbent driver. } \\
\text { Doesn't necessarily know the owner. }\end{array}$ & 8.95 & \\
\hline & Casual driver & $\begin{array}{l}\text { Taxi-less driver who waits in the rest areas } \\
\text { for the opportunity to rent a vehicle from an } \\
\text { incumbent or assistant driver for a few hours } \\
\text { or a day. }\end{array}$ & 9.1 & \\
\hline \multirow{2}{*}{$\begin{array}{l}\quad \text { Akouédo dump } \\
\text { Waste storage and } \\
\text { burning site; recovery, } \\
\text { recycling and sale } \\
\text { activities; market } \\
\text { gardening; waste } \\
\text { pickers are directly } \\
\text { exposed. }\end{array}$} & Buyer & $\begin{array}{l}\text { Located outside or on the edge of the dump. } \\
\text { Buys recovered waste by the kilo from waste } \\
\text { pickers, stores it and resells wholesale waste } \\
\text { items to various industries. }\end{array}$ & 11.89 & \multirow[t]{6}{*}{8.73} \\
\hline & $\begin{array}{l}\text { Service and } \\
\text { processing } \\
\text { activity }\end{array}$ & $\begin{array}{l}\text { Worker on the edge of the dump. This group } \\
\text { includes traders selling food, tobacco and } \\
\text { drinks, or carriers and waste processors } \\
\text { selling waste for a higher price (for example } \\
\text { by sewing up charcoal bags). }\end{array}$ & 8.89 & \\
\hline \multicolumn{4}{|l|}{ Social microcosm } & \\
\hline \multirow{3}{*}{$\begin{array}{l}\text { Village chiefdom } \\
\text { collecting fees } \\
\text { Many immigrants } \\
\text { living in insecure } \\
\text { conditions } \\
\text { Hierarchy related to } \\
\text { nationality }\end{array}$} & $\begin{array}{l}\text { Multiple-job } \\
\text { worker }\end{array}$ & $\begin{array}{l}\text { Combines waste picking and recovery on the } \\
\text { dump with one or more, less exposed } \\
\text { activities such as market gardening, waste }\end{array}$ & 8.27 & \\
\hline & & & & \\
\hline & $\begin{array}{l}\text { Waste picker } \\
\text { with just one } \\
\text { job }\end{array}$ & $\begin{array}{l}\text { Picks waste on the dump and sells waste } \\
\text { materials by the kilo. }\end{array}$ & 6.49 & \\
\hline
\end{tabular}

Figure 7. Summary table of occupational sectors and status categories and corresponding RCI values for each study site.

At this stage, RCI- EF comparisons remain limited for the various worker categories studied. Nevertheless, a first observation is that RCI values appear to be inversely proportional to the emissions measured on the study sites (Figure 8). Dump waste workers, with the lowest RCI scores in the sample, were observed to be the group most exposed to TPM (Total Particulate Matter, including black and organic carbon). 


\begin{tabular}{|l|l|l|}
\hline & $\begin{array}{l}\text { RCI } \\
\text { (out of 16) }\end{array}$ & $\begin{array}{l}\text { Emission Factor } \\
\text { (Total particulate matter) } \\
\mathrm{g} / \mathrm{kg}\end{array}$ \\
\hline Dump workers & 8.73 & 88 \\
\hline Lubafrique's smokers & 9.42 & 55 \\
\hline Adjamé's Taxi drivers & 10.21 & 53 \\
\hline
\end{tabular}

Figure 8. Relation between RCI values and the emissions measured on the study sites (EF values taken from Keita et al., 2018).

\section{Practices for living better with pollution}

The comparison between groups shows that there were two different types of practices on the three sites with regard to 'living better with' air pollution. On the one hand, there were practices to reduce exposure: wearing protection (mainly masks) - which remained rare on the three sites, diversifying activities (dump site), adapting working hours (and hence the length of exposure for smokers and taxi drivers), or maintaining vehicle (taxi drivers).

On the other hand, some practices were used to resist the health effects of pollution: adopting lifestyle habits, adapting diet and personal hygiene and exercising to enable the body to 'resist' pollution. The consumption of condensed milk, particularly of the brand name 'Bonnet Rouge', was thought both to make the body stronger and to 'cleanse' it by removing pollutants, smoke and dust: 'Milk helps the smoke, the black stuff, to come out when I cough ..., my spit becomes black. I know for myself that the nasty stuff comes out; so (...) milk cleans my heart.' (Malian home help, February 2017). The black spit was here considered a good sign of the efficiency of the nutritional treatment.

\section{Strategies to transfer vulnerability to pollution between individuals in different status categories}

Strategies to transfer vulnerabilities between workers in different social status categories were observed. Taxi drivers employed an assistant or a casual driver; the mums recruited a smoking helper; workers who have managed to save up a small amount of capital on the dump delegated the most difficult tasks to the newcomers, such as waste cleaning, carrying and processing. A middle-aged fish smoker mum employing a helper explained: 'I take people to smoke because the fire makes me tired. So I find some girls and pay them.' (Ivorian owner of a fish business, March 2017).

In each occupational sector, the only hope for a better future of the most exposed workers -usually those with the lowest occupational status in their socio-economic hierarchy - was to change jobs. One strategy was occupational advancement, whenever possible. Another strategy was to leave their job. This 'exit' strategy, however, relied on saving enough money to start over in another business less exposed to pollution or to train in a different occupation.

Finally, there was a more rarely implemented strategy, to invest in the very long term for future generations, which was mainly encountered in women and younger workers (male or female) at the smoking and dump sites. Moussa thus observed that: 'We must do 
something for our children so that when they grow up, they don't also work on [the dump] and get tired like we do. If we keep fighting, it's because of that, because of them.' (Ivorian intermediary salesperson on the Akouédo dump, April 2017). Nonetheless, access to education, and ultimately to a job protected from air pollution, was not guaranteed for the second generation of waste pickers on the Akouédo dump.

\section{Discussion}

We addressed the issue of 'living with' air pollution in Abidjan through the perspective of a 'pragmatic sociology of environmental risks'. Conceiving air pollution as an 'ordinary risk', we investigated the representations and practices of facing risk in three occupational groups exposed daily, without prejudging the asymmetries between or within these occupations. We then built a 'Risk Culture Indicator' in order to evaluate risk handling and to establish comparisons between the groups. Our findings are an indication of the value of the pragmatic position not to assume of inequalities - which ultimately emerge empirically. This approach is an example of the advantages of crossing analysis framework to deepen our understanding of a subject.

Resisting practices towards pollution, and more broadly risk handling, were also interpreted using the cultural approach. Along with Douglas and Wildavsky (1982), who described risk as a cultural construct reflecting a particular world view, our findings show how each worker prioritised the risk(s) he or she wanted to face, according to socioeconomic considerations. Furthermore, as in other cultures, nutritional practices to resist the health effects of pollution such as milk consumption seemed to refer to a 'hot-cold' system of beliefs which considered illness to be a result of humoral imbalance and strongly influenced treatment choice (García-Hernández, Vibrans, Rivas-Guevara, \& Aguilar-Contreras, 2015).

However, mobilising the sociology of Bourdieu (1980, 1994, 2003) allowed a deeper characterisation of risk culture towards air pollution. We showed that when dealing with air pollution, workers reproduced existing social inequalities related to their occupational fields. Aside from the source's polluting effect, different parameters seemed relevant for understanding the relationship between emission factors, exposure and RCI scores. First, length of exposure: changes in the RCI values observed for the different categories of women smokers were correlated with length of exposure to the source of pollution. The lowest RCI was linked to the greatest length of exposure. Secondly, distance to the source of pollution: at the dump, the workers closest to the source had the lowest RCIs. So, direct exposure to air pollution did not predict the social perception of experienced risk, in this case simply regarded as characteristic of work. To integrate status-related RCI changes and better quantify health risks, these relationships should be further investigated on cohorts of people simultaneously monitored for exposure to pollution, health problems and social vulnerability. Thirdly, the social determination of health: the coping strategies to resist the health effects of pollution revealed relationships of dominance inside the occupational groups: the workers holding the highest occupational statuses in their sector shifted the risk on to the workers at the bottom of the hierarchy by removing themselves from the most exposed tasks.

In light of a wider literature, we suggest comprehending these coping strategies as mechanisms reinforcing social hierarchies. Such mechanisms have been widely analysed by the French sociologist Pierre Bourdieu in a western context. We propose to refer to these dominant positions following his concept of 'capital'. The workers who were better 
able to reduce their exposure to pollution also had a higher economic capital: the ownership of the means of production - (smoking oven or cars for instance) a higher income, as well as a greater social capital - personal and occupational relationships, which could be mobilised in the pursuit of their interests. These resources allowed them to adjust their occupational practices in order to reduce the health effects of air pollution. Furthermore, 'dominant' workers - mums, taxis owners, waste buyers on the Akouedo dump - had de facto authority over workers on a lower level in the hierarchy - authority linked to age, economic power, knowledge and occupational network - which required obedience and induced dependence of other workers on them.

In our study, the risks relating specifically to air pollution are structured by and form part of wider risks, such as those resulting from poverty or social hierarchy. As Van Voorst (2015) demonstrated about the daily, lived experiences of flood risk in Jakarta, our findings show that an holistic approach towards risk and uncertainty is helpful to reach a more adequate understanding of people's daily life experiences with risk. We then agree with her suggestion to use a theory of risk, class and power in non-Western contexts, instead of using grand and popular theories of risk.

Our findings contribute therefore to the research works about environmental inequalities, especially those showing that individuals and communities with lower socioeconomic status are exposed to higher concentrations of criteria air pollutants (Hajat, Hsia, \& O'Neill, 2015). Our findings demonstrate both the role of environmental conditions in the reproduction of the existing social order and the role of social practices and hierarchy in the preservation or deterioration of bad environmental conditions. It particularly contributes to 'environmental suffering' research (Auyero \& Swistun, 2007, 2009) by highlighting the 'silent' dimension of living with risk in occupational situations (Thébaud-Mony, 2019).

This paper also provides a new methodological insight for assessing risk culture (the RCI). Although it deserves to be tested in other fields in order to evaluate its scientific potential, its pragmatic quality is useful in exposing social and occupational inequalities with regard to air pollution, and also in preventing health risks by going past conventional quantitative assessments towards a better understanding and integration of the social, economic and cultural dimensions of exposure. We believe RCI scores could be analysed on their own but, we recommend triangulating with qualitative methods to have an in depth outlook and an efficient analysis of field data.

\section{Conclusion}

This article is an attempt to characterise 'living with air pollution' in Abidjan on three study sites representing various air pollution sources affecting different groups of workers in their daily activities. Firstly, empirical data about the social dimension of risk related to air pollution show that the working conditions and occupational practices in each group shaped specific representations of air pollution. Moreover, air pollution risk is managed with short- term strategies because it is often overshadowed by other, more urgent threats to livelihood.

Secondly, this article brings new insights about the relevance of Giddens's definition of risk culture in a non-western context. On one hand, our findings suggest that risk culture is the combination of a tangible experience of pollution (its reality), technical mediations staging that experience (objects and equipment), and existing social relationships (dominance relationships). Therefore, risk culture should no longer be conceived as 
the gap between objective data (environmental measurements) and subjective (social) perceptions, but as an integral part in the calculation of health risks.

On the other hand, it demonstrates that 'colonising the future', as a long-term risk management perspective, requires strategies to reduce overall vulnerability, and differs according to occupational status. For the most powerful in each occupational area, the strategy is to transfer the risk to the workers at the bottom of the industry hierarchy in the short term, thus increasing their individual 'resilience', and to make plans for the long term in the same industry. For the most vulnerable, the strategy is to 'hope' to move up the industry hierarchy, where there is a greater choice in terms of exposure levels, or to save up for the long term in order to leave the hazardous job permanently. We can hereby conclude that occupational experiences of air pollution largely follow the contours of class division in Abidjan city. In other words, like for other risks (Curran, 2013; Van Voorst, 2015), we argue that social hierarchies determine the risk culture of air pollution.

Thirdly, we consider this paper as an illustration of the potential lying in the combination of qualitative methodology (interviews and focus groups) and calculation of RCIs to reveal the granularity of occupational vulnerability to environmental conditions.

Finally, our findings about the differential exposure to air pollution could have implications for the operational management of environmental health disparities from a public health perspective.

\section{Disclosure statement}

No potential conflict of interest was reported by the authors.

\section{Funding}

We performed this research within the framework of two projects: 1- The Dynamics-AerosolChemistry-Cloud Interactions in West Africa (DACCIWA), supported by the European Union Seventh Framework Programme [FP7/2007-2013] and the IDEX SAREAH supported by the French research agency (ANR).

\section{Supplementary material}

Supplemented data of this article can be accessed here.

\section{References}

Auyero, J., \& Swistun, D. (2007). Confused because exposed. Towards an ethnography of environmental suffering. Ethnography, 8(2), 123-144.

Auyero, J., \& Swistun, D. (2009). Flammable. Environmental suffering in an argentine shantytown. Oxford: Oxford University Press.

Bardin, L. (1977). L'analyse de contenu. Paris: Presses Universitaires de France.

Barraza, F., Maurice, L., Uzu, G., Becerra, S., Ochoa-Herrera, V., Lopez, F., ... Schreck, E. (2017). Distribution, content and health risk assessment of metal(loid)s in small-scale farms in the Ecuadorian Amazon: An insight on oil activities impacts. Science of Total Environnement, 3 (622-623), 106-120.

Barthe, Y., De Blic, D., Heurtin, J., Lagneau, É., Lemieux, C., Linhardt, D., ... Trom, D. (2013). Sociologie pragmatique: Mode d'emploi. Politix, 103(3), 175-204.

Becerra, S., Juteau-Martineau, G., Maestripieri, N., \& Maurice, L. (2016). Vivre avec le risque sanitaire environnemental et les activités pétrolières en Amazonie équatorienne: Une culture 
d'urgence. In S. Becerra, M. Lalanne, \& J. Weisbein (Eds.), Faire face au risque dans les sociétés contemporaines (pp. 199-211). Toulouse: Octarès Editions.

Becerra, S., Saqalli, M., Gangneron, F., \& Dia, H. A. (2016). Everyday vulnerabilities and "social dispositions" in the Malian Sahel, an indication for evaluating future adaptability to water crises? Regional Environmental Change, 16(5), 1253-1265.

Belland, M. (2017). Pollution de l'air et culture du risque à Abidjan. Etude de trois professions évoluant sur des sites fortement pollués à Abidjan (Unpublished master's thesis). Sciences Po Toulouse.

Blesius, J.-C. (2013). Discours sur la culture du risque, entre approches négative et positive. Vers une éducation aux risques? Géographie et cultures, 88, 249-265.

Boudia, S., \& Jas, N. (2013). Toxicants, health and regulation since 1945. London: Pickering and Chatto.

Boudia, S., \& Jas, N. (2015). Gouverner un monde dangereux. Les risques techniques, sanitaires et environnementaux. Histoire des sciences, 3(1), 380-397.

Boudia, S., \& Jas, N. (2019). Gouverner un monde toxique. Versailles: Quae, coll. « Sciences en questions ».

Bourdieu, P. (1979). Les trois états du capital culturel. Actes de la recherche en sciences sociales, 30, 3-6.

Bourdieu, P. (1980). Le sens pratique. Paris: Minuit, « Le sens commun ».

Bourdieu, P. (1994). Stratégies de reproduction et modes de domination. Actes de la recherche en sciences sociales, 105, 3-12.

Bourdieu, P. (2003). La fabrique de l'habitus économique. Actes de la recherche en sciences sociales, 150, 79-90.

Calès, M. (2016). La culture du risque de contamination en territoire pétrolier, L'exemple de Dayuma et Pacayacu en Amazonie Equatorienne (Unpublished master's dissertation). Sciences Po Toulouse. Retrieved from http://www.monoil.ird.fr/communication-et-valorisation/mem oires-d-etudiants

Curran, D. (2013). Risk society and the distribution of bads: Theorizing class in the risk society. The British Journal of Sociology, 64(1), 44-62.

De Vlieger, I., De Keukeleere, D., \& Kretzschmar, J. G. (2000). Environmental effects of driving behaviour and congestion related to passenger cars. Atmospheric Environment, 34(27), 4649-4655.

Desmond, N., Prost, A., \& Wight, D. (2012). Managing risk through treatment-seeking in rural north-western Tanzania: Categorising health problems as malaria and nzoka. Health, Risk \& Society, 14(2), 149-170.

Douglas, M., \& Wildavsky, A. (1982). Risk and culture, an essay on the selection of technological and environmental dangers. London: University of California Press.

Durand, S. (2014). Vivre avec la possibilité d'une inondation? Ethnographie de l'habiter en milieu exposé ... et prisé (Doctoral dissertation). Aix Marseille Université, Aix en Provence. Retrieved from https://tel.archives-ouvertes.fr/tel-01162551

García-Hernández, K.-Y., Vibrans, H., Rivas-Guevara, M., \& Aguilar-Contreras, A. (2015). This plant treats that illness? The hot-Cold system and therapeutic procedures mediate medicinal plant use in San Miguel Tulancingo, Oaxaca, Mexico. Journal of Ethnopharmacology, 163, $12-30$.

Giddens, A. (1990). The consequences of modernity. Cambridge: Polity Press.

Hajat, A., Hsia, C., \& O'Neill, M. S. (2015). Socioeconomic Disparities and Air Pollution Exposure: A Global Review. Current Environmental Health Reports, 4(2), 440-450.

Hecht, G. (2019). Air in the time of oil. Provocations series, in conjunction with UCI's "Fire \& Ice: The Shifting Narrative of Climate Change" conference. Retrieved from https://www.academia. edu/38274479/Air_in_the_Time_of_Oil

Kassi-Djodjo, I. (2010). Rôle des transports populaires dans le processus d'urbanisation de la ville d'Abidjan. Les Cahiers d'Outre-Mer, 63(251), 391-402.

Keita, S., Liousse, C., Yoboué, V., Dominutti, P., Guinot, B., Assamoi ... Roblou, L. (2018). Particle and VOC emission factor measurements for anthropogenic sources in West Africa. Atmos. Chem. Phys, 18, 7691-7708.

Lemieux, C. (2018). La sociologie pragmatique. Paris: La Découverte.

Lin, K.-H., \& Chang, C.-Y. (2013). Everyday crises: Marginal society livelihood vulnerability and adaptability to hazards. Progress in Development Studies, 13(1), 1-18. 
Liousse, C., Assamoi, E., Criqui, P., Granier, C., \& Rosset, R. (2014). Explosive growth in African combustion emissions from 2005 to 2030. Environ. Research Letters, 9(3), 1-10.

Nweke, O. C., \& Sanders, W. H., III. (2009). Modern environmental health hazards: A public health issue of increasing significance in Africa. Environmental Health Perspectives, 117(6), 863-870.

Racinés Izquierdo, D. (2017). Cultura de riesgo: Impacto social de la actividad petrolera en comunidades shuar y kichwa de la parroquia de Dayuma, Francisco de Orellana (Master's dissertation). Universidad San Francisco de Quito. Retrieved from http://repositorio.usfq.edu. ec/handle/23000/7077

Becerra, S (2016, novembre 22-24). Ignorance et contaminations pétrolières: l'expérience sociale du risque en Equateur. Lettre de l'INSHS.

Renn, O., Burns, W. J., Kasperson, J. X., Kasperson, R. E., \& Slovic, P. (1992). The social amplification of risk: Theoretical foundations and empirical applications. Journal of Social Issues, 48(4), 137-160.

Revet, S., \& Langumier, J. (eds). (2015). Governing disasters. beyond risk culture: Beyond risk culture. The sciences po series in international relations and political economy. Basingstoke: Palgrave Macmillan.

Thébaud-Mony, A. (2019). Les travailleurs sont-ils les « invisibles » de la santé environnementale ou ... les « damnés de la terre? ». Écologie \& politique, 58(1), 69-82.

Torny, D. (2013). Managing an everlastingly polluted world: food policies and community health actions in the French West Indies. In S. Boudia \& N. Jas (Eds.), Toxicants, health and regulation since 1945 (pp. 117-134). London: Pickering and Chatto.

Tulloch, J., \& Lupton, B. (2002). 'Risk is part of your life': Risk epistemologies among a group of Australians. Sociology, 36(2), 317-334.

Tulloch, J., \& Lupton, B. (2003). Risk and everyday life. London: Sage Publication.

Turner, B. A. (1981). Organizational responses to hazard. In H. Kunreuther (Ed.), Risk. A seminar series (pp. 49-86). Laxenburg: International Institute for Applied Systems Analysis.

Van Voorst, R. (2015). Applying the risk society thesis within the context of flood risk and poverty in Jakarta, Indonesia. Health, Risk \& Society, 17(3-4), 246-262.

WHO. (2016). Air pollution rising in many of the world's poorest cities, Press release, 12 May 2016. Geneva. Retrieved from http://www.who.int/news-room/detail/12-05-2016-airpollution-levels-rising-in-many-of-the-world-s-poorest-cities

Wisner, B., Blaikie, P., Cannon, T., \& Davis, I. (1994/2004). At risk: Natural hazards, people's vulnerability, and disasters. London: Routledge.

Xu, H., Léon, J.-F., Liousse, C., Guinot, B., Yoboué, V., Akpo, A. B., ... Cao, J. (2019). Personal exposure to PM2.5 emitted from typical anthropogenic sources in southern West Africa: Chemical characteristics and associated health risks. Atmospheric Chemistry and Physics, $19,6637-6657$.

Yao-Kouassi, C. (2010). A la recherche d'une synergie dans la gestion des déchets ménagers en Côte d'Ivoire, cas du district d'Abidjan (Doctoral dissertation). Université du Maine, Le Mans. Retrieved from http://cyberdoc.univ-lemans.fr/theses/2010/2010LEMA3006 